\title{
A Novel Approach on College English Cooperative Learning Platform Design and Its Application
}

\author{
XIE Qiong ${ }^{1, a}$ \\ ${ }^{1}$ College of Public Education, Jiangsu University of Science \& Technology (Zhang Jiagang \\ Campus), Zhang Jiagang 215600, China \\ aellenqi@163.com
}

Keywords: English Cooperative Learning, Wiki, College English

\begin{abstract}
In this study, social constructivist theory, distributed cognition theory, group dynamics theory and the feedback effect theory are consulted. From the perspective of teaching design, combined with the network collaborative learning activity in the learning process, a system of College English cooperative learning activities under the Wiki environment is put forward. Through the ISM analysis method, the inner relationship between elements based on wiki college English cooperative learning mode is constructed, and then through the contrast test, questionnaire and interview the feasibility and effectiveness of the learning mode is verified. This study provides the design of the wiki learning platform and learning activities, such as the formation of college English cooperative learning mode based on wiki. On the basis of the model the effectiveness of the wiki learning platform is verified and thus we hope to promote college English education with wiki applied to teaching process.
\end{abstract}

\section{Introduction}

With the development of information technology, many of the researchers paid a great deal of attention to and did a lot of research on how to effectively use computers to support English-learning. Wiki, a typical kind of Web2.0 application software, features quite consistent with the spirit of collaborative learning, for through the established system wiki site can provide multiplayer online simultaneously modifying, editing content, and other functions, with each user freely contributing their resources to the wiki site, which is supposed to play a very important role in college English teaching. The wiki site, collaborative learning and college English teaching can be integrated into a college English teaching program as well as a new learning environment, thus to explore an effective way worthy of further study and discussion for college English learning [1-2].

Education, virtually accompanied by major changes in human society, is now faced with its own transformation and the growing trend of globalization and more importantly, is raised new demands, i.e., It is expected to be open-ended and socialized and the educated should have the ability of autonomic learning. Constructivists view that learning is essentially a process of active construction of knowledge, during which process the individuals interact with the outside world in a certain social interaction, social norms, social and cultural background of the product, based on previous experience and knowledge, and thus construct their own knowledge and understanding of the new process, which is the significance of the generation process. In other words, introduction of social software dramatically changed the status quo of education [3]. Wiki technology, with its collaboration, sharing features, specific information dissemination tools, collaboration tools, educational applications of interactive tools for the construction of new knowledge in the process of negotiation, provides a strong support for the dialogue between teaching and learning.

This study attempts to build a new social collaborative learning model by way of combining the characteristics of Wiki. We found that through teaching practice, with the benefits of Wiki techniques that can be put to good use, we could carry out social collaborative learning. However, so far Wiki has been applied as a supplementary means, not covering the entire process of learning. In addition, some functions of Wiki technology itself needs to be further developed in order to be 
more conducive to support social collaborative learning. This study provides learning resources, helps build learning platform and design learning activities under the Wiki-based collaborative learning platform. I hope it may be of great help in promoting the application of Wiki technology in education.

\section{Wiki-based collaborative learning model}

Wiki is an open network and a hypertext system for collaborative creative people, whose main feature is to encourage users to edit. It does not restrict the user login or ever having an independent account in the community; instead it is to construct an easy-to-edit environment that allows anyone to edit and modify the content for the community. In short, wiki, as an open, sharing, collaboration workplace, can make and modify HTML pages, record the system, change the layout of all systems, and provide functionality to change. Wiki restores the site to allow any person to access it quickly and easily add, delete, edit all content and usually not to have to log in, and it is particularly suitable for learning teamwork [4-6]. Wiki system may also include a variety of support tools, allowing users to easily track the history of changes in the wiki, or allowing users to discuss and resolve disagreements about wiki content.

Social constructivist learning theory and distributed cognition theory being the theoretical basis, with the above analysis of collaborative learning and the analysis on the support of wiki technology for collaborative learning, and together binding wiki properties, we constructed the following Wiki-based collaborative learning model, as shown in Figure 1.

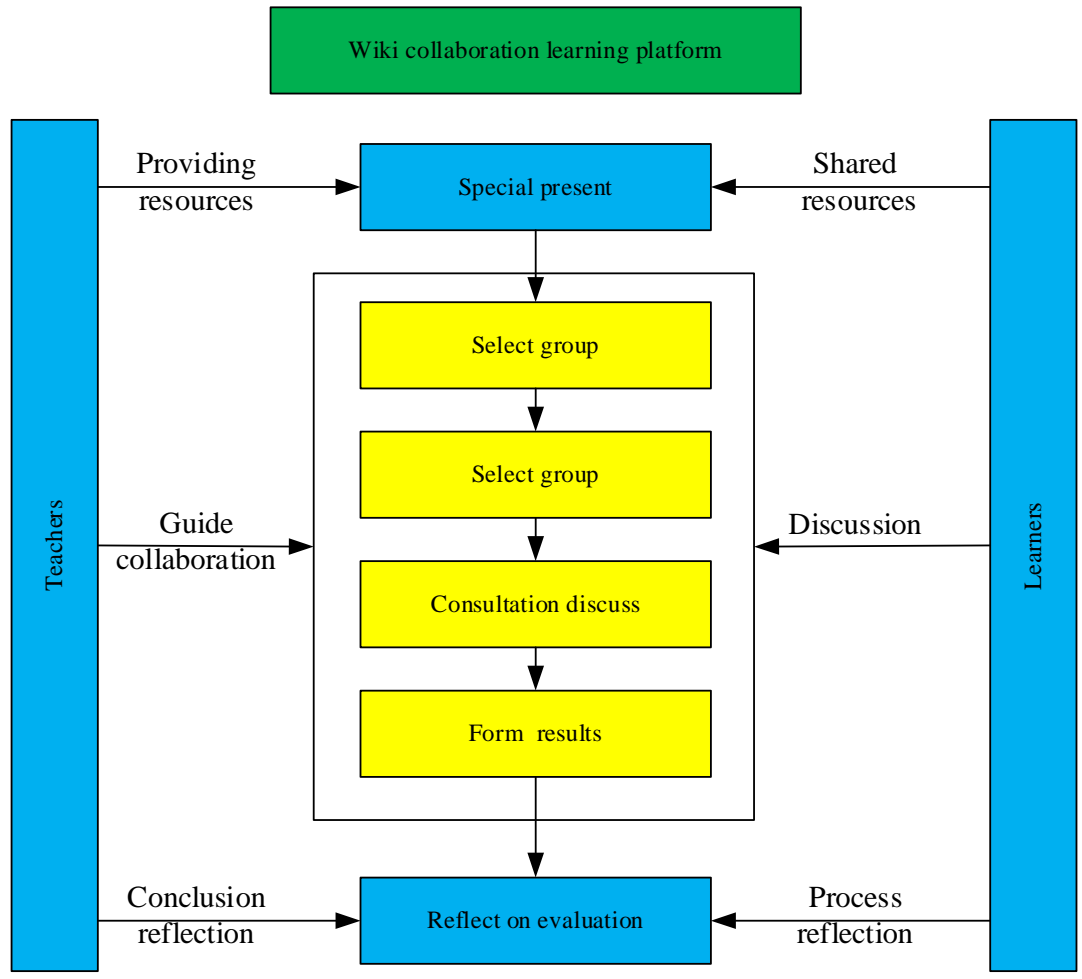

Figure 1. Wiki-based collaborative learning model

Wiki-based collaborative learning is a social network collaborative learning model or strategy based on the integration of Wiki collaborative features and characteristics of collaborative learning on their own proposed. It refers to the use of Wiki technology to build collaborative learning environment, by which learners, around related topics, issues or task, build the academic knowledge, complete collaborative negotiation so as to solve specific problems and tasks, and ultimately enhance the ability of problem solving, innovation and other advanced cognitive skills of a learning mode [7-8]. This mode supports the use of Wiki environment to achieve social collaboration, so that different learners and experts in different places or disciplines together participate in the construction of knowledge. Wiki technology can be extended to the management of collaborative 
learning, i.e., teachers can monitor and guide learners through management tools provided by the platform, which is more convenient and effective. Besides, Wiki shares learning resources, provides a more effective way that all participants could assist designers analyzing, planning, designing, communicating and implementing collaborative learning. Hence, these features of Wiki change the customary relationship between teaching and learning and make a new important learning strategy.

\section{Wiki-based architecture for College English collaborative learning platform}

In this study, the author will focus on the module design for collaborative learning activities based on the integration of both important elements of college English and wiki techniques. The framework of Wiki platform is shown in Figure 2, in accordance with the foregoing analysis, the wiki platform is built both for the instructor and collaborative teams. The instructor is the organizer of the group activities, platform builders and maintainers, while collaborative teams are the platform resources since they are active participants and builders as well. Both, the instructor and collaborative groups, share different responsibilities.

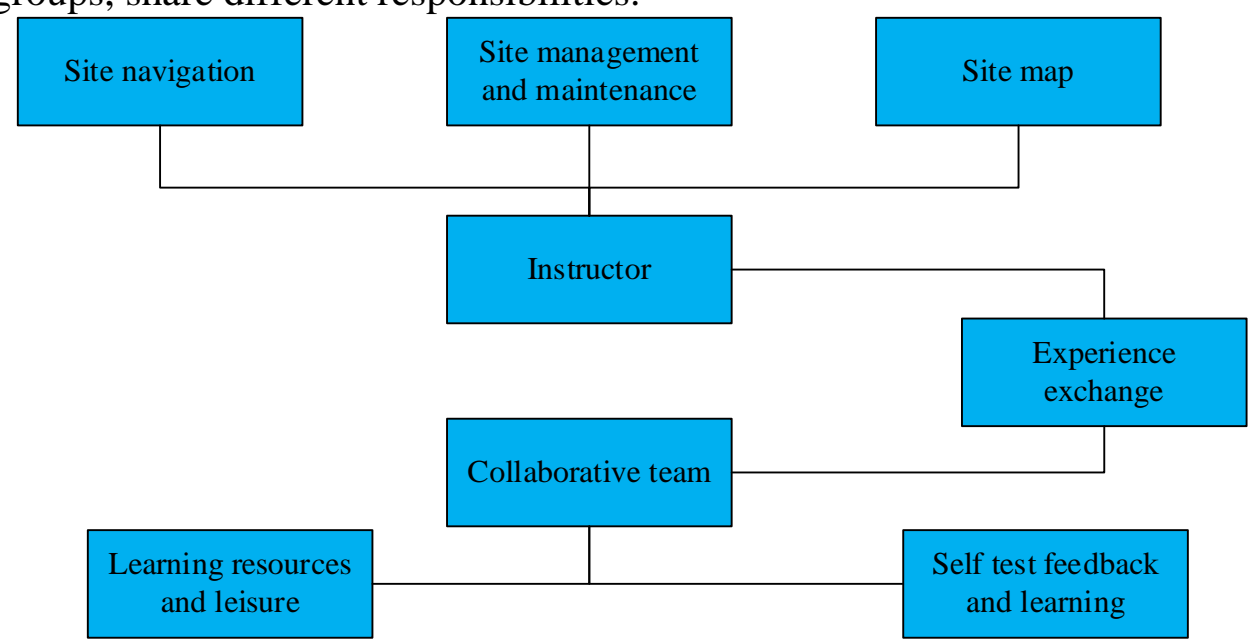

Figure 2. The architecture of College English collaborative learning platform based on wiki

Wiki-based collaborative learning platform for college English includes the following modules:

Site navigation. Site navigation consists of two parts, pre-study guidance, learning tasks. Pre-study guidance includes two aspects, first, the instructions on how to use the platform, and second, the arrangements for collaborative activities. Pre-study guidance is meant to get learners familiar with wiki operation platform and understanding the relevant rules of collaborative learning, helping them to quickly and efficiently carry out their activities. Learning tasks section contains five collaborative teams in each phase of the mission, each phase of the mission including six sub-tasks, namely listening, reading, vocabulary, translation, writing and cloze.

Site Map. Establishment Sitemap forum is to facilitate collaborative team members to quickly and easily search for information and the instructor to effectively manage resources. Site map inside adopts tree resources management, where each resource module has a site, so that we can see learning progress of each group to assist the instructor to supervise.

Learning Resources. Learning Resources Forum is originally created by the instructor, and team members and the instructor can modify and update the contents. Every now and then, the instructor organizes this section of resources for the convenience of the learners. Learning resources and tasks cover five aspects, and are correspondingly divided into six sections: listening, reading, vocabulary, writing, translation, and cloze. The more learners participate in, the more abundant learning resources there will be.

Leisure Inn. Leisure Inn is a module for learners to relax, whose main contents include recitation of classic English essays, English songs and classic English movie dialogues. Leisure Inn will help to stimulate learners' interest in learning and to promote exchanges between members as well. 
Self-reflection. Self-reflection module allows team members to evaluate and reflect on the task of this group and the gap on the level of cooperation and the degree of interaction between their group and others; learners make the summary and evaluation for individual performance as well as that of their group throughout each activity and the whole course. Every self-reflection functions as a learning stage.

Exchange of experience. Experience exchange area can be used between members of the group inside, between different groups, and can be used for communication and exchange between the group and the teacher. It may include exchanges of views about the examination and the problems encountered and so on. Group members can express their views on a particular issue, and they can discuss through consultations to form a relatively systematic knowledge. This area is conducive to encourage each other and solve problems among members. And members can improve motivation, increase self-confidence and sense of community of learners by participating in collaborative activities.

Website management and maintenance. Wiki platform ensures the smooth operation of the normal and necessary technical means, which is primarily the duty of the instructor. Through Wiki index toolbar, the instructor can check all the pages; by checking the functional modules and the content of organizing web, one can remove the redundant information to prepare a good resource to facilitate learners; by the meter toolbar board, one can freely add or remove modules; and by modifying the specific pages the function of wiki platform can be improved.

\section{Functional modules design for college English collaborative learning platform}

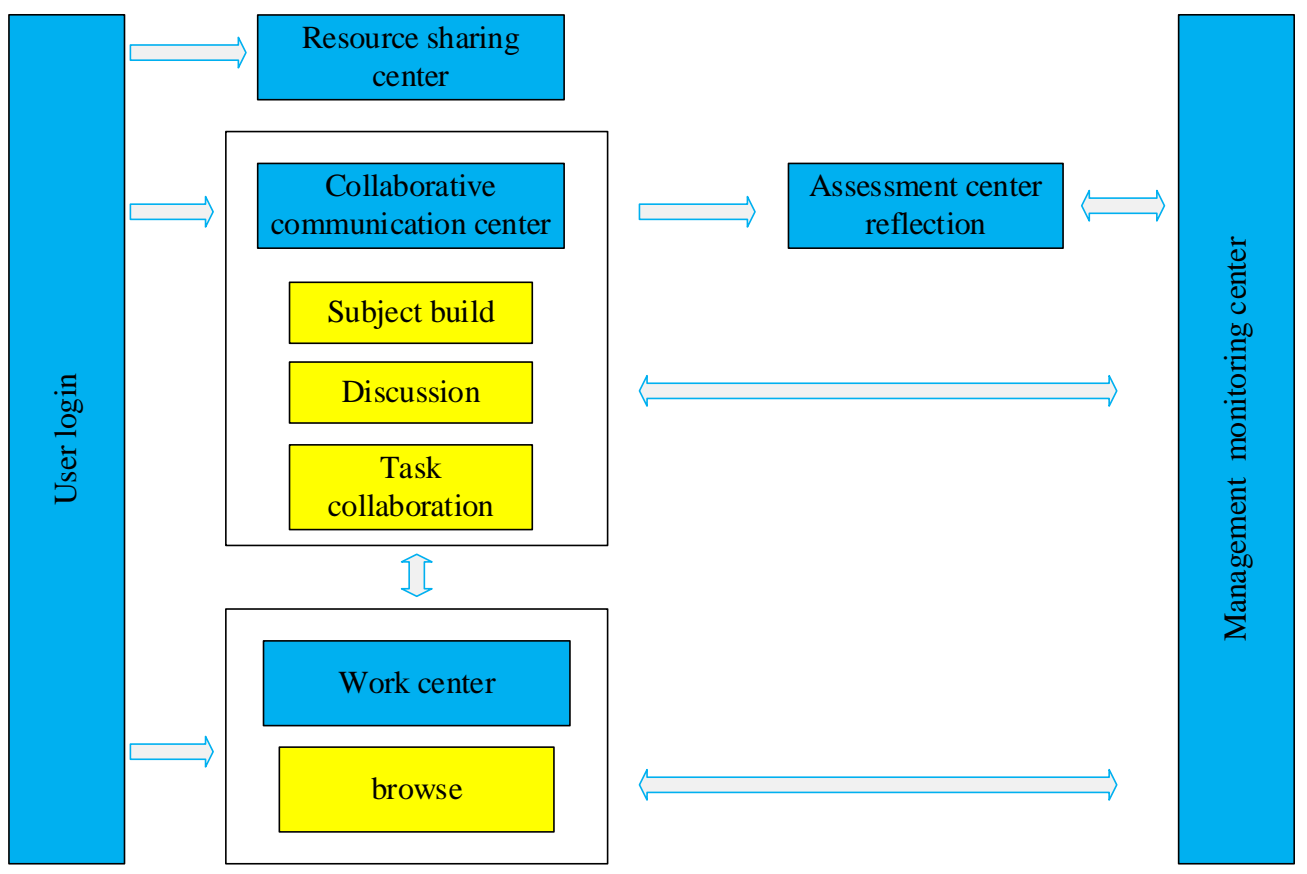

Figure 3. The functional modules for college English collaborative learning platform

According to the section of the social construction of collaborative learning model, combining the characteristics of existing Wiki engines, we chose wiki as the engine for collaborative social learning platform. With all Wiki features, the preliminary platform includes five functional modules, namely, resource centers, collaborating centers, work centers, evaluation and reflection center and management center. Block diagram of the system shown in Figure 3.

Resource Sharing Center. Learners in social collaborative learning require a lot of resources; so do the instructor when evaluating learners. The main function of Resource Center module is to collect and synthesize the related issues by way of using the Wiki technology, which consists of two modules: resource management and resource sharing. Resource Center module provides open available resources and comprehensive capabilities of resource management, making social 
collaborative learning more effectively carried out; while it offers the important support for the sharing of resources between teachers and learners. Both teachers and learners can become builders and managers of resources, not to mention sharing resources.

Collaboration exchange center. The module's main function is to carry out social collaborative learning, mainly by the central theme of the construction and the central issues discussed in three other functional modules, thus to achieve a good communication and collaboration between teachers and learners, between learners as well as between teachers. In addition to directly editing the Wiki page of the module by which teachers and learners communicate, one can also provide a powerful communication and collaboration service in the discussion area that enables teachers and learners to successfully carry out the theme of the construction, the issues discussed during collaborative learning activities and tasks.

Work center. The module offers specific service for teachers to guide learners to carry out social work and collaborative learning. Learners can turn to the center when in need and regain their learning dynamics. Also in the center they can assist their teachers post important notices.

Management center. Good management platform can effectively monitor both study and work. It not only provides comprehensive technical support for the development of collaborative learning community, but also provides a basis for evaluating the process of social collaborative learning, guaranteeing the entire community of social collaborative learning going forward in an orderly, shared stable and sustainable way.

Reflection and evaluation center. In social collaborative learning, reflection and evaluation module can record the details of learners in the process of social collaborative learning, based on which teachers and learners can carry out self-evaluation; teachers can also evaluate and reflect on learners' motivation. Here is a wide range of evaluation methods. Learners can have their own self-evaluation, and they can evaluate teachers or other members of the group, and vice versa.

\section{Conclusion}

This paper aims to construct College English cooperative learning mode from the perspective of collaborative learning, by integrating the three elements, network leaning platform, wiki technology, College English learning, with the hope of making a useful exploration for the current wiki Applied Technology Education and developing and applying a wiki-based collaborative learning platform for college English. From the theoretical and practical aspects the paper discussed collaborative learning mode based on the English wiki. In the theoretical stage, we proposed collaborative learning activities and the teaching design with the support of wiki techniques. Based on the theory of collaborative learning and feedback effects we first put forward the constituent elements of College English under wiki collaborative learning activities (collaborative group, the instructor, network environment, learning tasks, learning outcomes, evaluation, communication and sharing of information feedback and adjustments), and analyzed the hierarchical relationship between the elements, which can be elaborated as follows, active instructor and guiding organization, which is a major player in collaborative activities; learning tasks are the core activities; learning effect is a way to measure learning with the use of interpretative structural modeling guidelines for the task; evaluation is based on the active process adjustments to ensure communication and sharing of feedback and information to adjust the learning activities; the network environment is the active supporting conditions.

This paper proposed the learning activities in three stages of college English teaching under the wiki collaborative learning environment, which refer to the phase of design, the phase of implementation and that of evaluation and adjustment. In practice, according to theories, the stage model of instructional design is proposed and a wiki-based collaborative learning platform for college English is built, including site navigation, site map, learning resources, recreation inn, self-reflection, exchange of experiences and website management and maintenance. This study presented the design of Wiki-based College English Cooperative Learning Activities, which, as we hope, would benefit English learners. Additionally, its teaching model is reasonable, feasible and useful. 


\section{References}

[1] Shih R C. Can Web 2.0 technology assist college students in learning English writing? Integrating Facebook and peer assessment with blended learning[J]. Australasian Journal of Educational Technology, 2011, 27(5): 829-845.

[2] Chao Y C J, Lo H C. Students' perceptions of Wiki-based collaborative writing for learners of English as a foreign language[J]. Interactive Learning Environments, 2011, 19(4): 395-411.

[3] Wichadee S. Using wikis to develop summary writing abilities of students in an EFL class[J]. Journal of College Teaching \& Learning (TLC), 2011, 7(12).

[4] TREnTIn G. Using a wiki to evaluate individual contribution to a collaborative learning project[J]. Journal of Computer Assisted Learning, 2009, 25(1): 43-55.

[5] Denton D W. Enhancing instruction through constructivism, cooperative learning, and cloud computing[J]. TechTrends, 2012, 56(4): 34-41.

[6] Turgut Y. EFL learners' experience of online writing by PBWiki[C]//World Conference on Educational Multimedia, Hypermedia and Telecommunications. 2009, 2009(1): 3838-3847.

[7] Miyazoe T, Anderson T. Learning outcomes and students' perceptions of online writing: Simultaneous implementation of a forum, blog, and wiki in an EFL blended learning setting[J]. System, 2010, 38(2): 185-199.

[8] Slotter E B. Using wiki contributions to induce collaborative learning in a psychology course[J]. International Journal of Technology in Teaching and Learning, 2010, 6(1): 33-42. 